\title{
Disease Activity Cutoff Values in Initiating Tumor Necrosis Factor Inhibitor Therapy in Ankylosing Spondylitis: A German GO-NICE Study Subanalysis
}

\author{
Jürgen Braun (D), Xenofon Baraliakos (D), Uta Kiltz (i), Klaus Krüger, Gerd R. Burmester (iD, \\ Siegfried Wassenberg, and Matthias H. Thomas
}

ABSTRACT. Objective. International recommendations for the management of axial spondyloarthritis including ankylosing spondylitis (AS) recommend a Bath Ankylosing Spondylitis Disease Activity Index (BASDAI) level of disease activity of $\geq 4$ to initiate treatment with biologics. We aimed to evaluate the level of disease activity used to initiate tumor necrosis factor inhibitor (TNFi) treatment and the level of responses to treatment based on different BASDAI cutoffs.

Methods. This is a posthoc analysis of the noninterventional, prospective, GO-NICE study in the subgroup of biologic-naive AS treated with golimumab (GOL) $50 \mathrm{mg}$ subcutaneously once monthly. Results. Of the 244 biologic-naive AS patients at baseline, 70.5\% had a BASDAI $\geq 4$ (Group 1), $14.3 \%$ had 2.8 to $<4$ (Group 2), and $15.2 \%$ had even $<2.8$ (Group 3). A total of 134 patients (54.9\%) completed the 24-month observational period. The mean BASDAI in Groups 1, 2, and 3 was initially $5.9 \pm 1.3,3.4 \pm 0.4$, and $2.0 \pm 0.8$, decreased to $2.2 \pm 2.0,1.9 \pm 1.2$, and $1.0 \pm 1.2$ within 3 months (all $\mathrm{p}<0.0001$ vs baseline), and decreased significantly to $2.2 \pm 1.7,1.9 \pm 1.7$, and $1.4 \pm 1.0$ at Month 24 (all p < 0.005), respectively. BASDAI 50\% improvement was noted in 68.8\%, 44.8\%, and $45.2 \%$ of patients at Month 3, and in $84.9 \%, 61.9 \%$, and $55.0 \%$ at Month 24 .

Conclusion. TNFi treatment was initiated in almost a third of AS patients with lower disease activity states as assessed by BASDAI cutoff of $\geq 4$. Patients with a BASDAI between 2.8 and $<4$ appeared to benefit significantly from GOL treatment, while patients with BASDAI $<2.8$ did not. This finding should lead to a reevaluation of the established BASDAI cutoff of $\geq 4$. (First Release July 152019 ; J Rheumatol 2020;47:35-41; doi:10.3899/jrheum.181040)

Key Indexing Terms:

ANKYLOSING SPONDYLITIS BIOLOGICAL THERAPY OBSERVATIONAL STUDY

From the Rheumazentrum Ruhrgebiet, Herne and Ruhr University Bochum, Herne; Rheumatologisches Praxiszentrum München; Department of Rheumatology and Clinical Immunology, Charité-Universitätsmedizin, Berlin; Rheumazentrum Ratingen, Ratingen; Medical Affairs, MSD Sharp \& Dohme GmbH, Haar, Germany.

The work was supported by MSD Haar. MSD had a role in the study design and in the collection, analysis, and interpretation of the data, the writing of the manuscript, and the decision to submit the manuscript for publication.

M. Thomas is a full-time employee of MSD Sharp \& Dohme GmbH, Haar. $U$. Kiltz received an unrestricted grant from AbbVie. G.R. Burmester received lecture and/or consulting fees from MSD. K. Krïger received speaker fees and research grants from AbbVie, MSD, and Pfizer.

J. Braun, MD, Rheumazentrum Ruhrgebiet, Herne and Ruhr University Bochum; X. Baraliakos, MD, Rheumazentrum Ruhrgebiet, Herne and Ruhr University Bochum; U. Kiltz, MD, Rheumazentrum Ruhrgebiet, Herne and Ruhr University Bochum; K. Krüger, MD, Rheumatologisches Praxiszentrum München; G.R. Burmester, MD, Department of Rheumatology and Clinical Immunology, Charité-Universitätsmedizin; S. Wassenberg, MD, Rheumazentrum Ratingen; M.H. Thomas, PhD, Medical Affairs, MSD Sharp \& Dohme GmbH.

Address correspondence to Prof. Dr. med. J. Braun, Rheumazentrum Ruhrgebiet, Ruhr-University Bochum, Claudiusstr. 45, D-44649 Herne, Germany.E-mail: sekretariat@rheumazentrum-ruhrgebiet.de

Full Release Article. For details see Reprints and Permissions at jrheum.org

Accepted for publication February 13, 2019.
Ankylosing spondylitis (AS), the "radiographic" part of the spectrum of axial spondyloarthritides, is a chronic inflammatory rheumatic disease with predominant involvement of the axial skeleton by both inflammation and new bone formation ${ }^{1}$. Treatment with TNFi is effective, as shown in a recent systematic review and a Bayesian network metaanalysis comprising 20 trials of 6 tumor necrosis factor- $\alpha$ inhibitors (TNFi) and 3220 participants ${ }^{2}$.

Ever since the first publication on the success of therapy with TNFi in patients with active $\mathrm{AS}^{3}$, the Bath Ankylosing Spondylitis Disease Index (BASDAI) ${ }^{4}$ cutoff of 4 and above has been used ${ }^{5}$, and published evidence from various sources support this approach ${ }^{6,7,8}$. Correspondingly, this cutoff value $\geq 4$ has been recommended for use in all major international guidelines ${ }^{9,10,11}$. The current Assessment of Spondyloarthritis international Society/European League Against Rheumatism (ASAS/EULAR) recommendations for patients with axial spondyloarthritis (axSpA) define active disease by Ankylosing Spondylitis Disease Activity Score (ASDAS) $\geq 2.1$ or BASDAI $\geq 4$. Historically, active disease has been defined by a BASDAI level of at least 4 , while ASDAS is the preferred measure today ${ }^{11}$. 
However, the BASDAI threshold value has been arbitrarily $\operatorname{set}^{3}$, and has never been thoroughly evaluated. This is in contrast to the ASDAS, which has been developed on a data-driven basis ${ }^{12,13}$. Accordingly, it has remained unclear whether patients with a lower BASDAI may also benefit from therapy with biologic agents. In our personal experience, this is an issue because young male patients, especially, tend to dissimulate and report low BASDAI scores, even though they may have high C-reactive protein (CRP) levels or strong evidence of axial inflammation by magnetic resonance imaging (MRI) ${ }^{14}$.

The assessment of disease activity in AS is based on clinical variables such as inflammatory spinal pain, laboratory variables such as $\mathrm{CRP}^{15}$, and MRI. Conversely, the predictive value of baseline (BL) CRP levels on clinical and radiographic outcomes in patients with AS has been documented in many studies ${ }^{16,17,18}$.

In the GO-RAISE study with golimumab (GOL) $50 \mathrm{mg}$ once monthly ${ }^{19,20,21}$, the drug was shown to be safe and effective in adult patients with AS. In that study, in AS patients treated with GOL, elevated CRP at BL or Week 14/Week 24 weakly predicted subsequent radiographic progression and modestly predicted residual spinal inflammation ${ }^{22}$.

We were interested in learning about the level of disease activity used in daily routine to start TNFi therapy, taking advantage of data obtained in the observational phase IV study GO-NICE performed in Germany, in which unselected patients with AS were treated with GOL $50 \mathrm{mg}$ once monthly and observed up to 24 months $^{23,24}$. In GO-NICE, clinical effectiveness was assessed in 501 patients with AS according to the German standard of care using the 10-point BASDAI to quantify disease activity ${ }^{4,25}$.

We performed a subgroup analysis of patients with AS who were categorized into 3 BASDAI groups and described regarding characteristics, treatment, and outcomes. In addition, we studied the influence of BL CRP values on clinical outcome variables in a real-world setting.

\section{MATERIALS AND METHODS}

This is a posthoc analysis of the noninterventional, multicenter, prospective, study GO-NICE (Non-Interventional Clinical Evaluation with GOlimumab) that was performed between 2010 and 2015 in a real-life setting by rheumatologists in 158 sites in all parts of Germany ${ }^{23,24}$. Patients were observed from BL up to 24 months through 8 visits performed every 3 months. Safety data were also collected, and have been reported previously ${ }^{23}$. GOL was prescribed by the treating physicians based on patients' need for the therapy and in accordance with the recommendations of the Summary of Product Characteristics $^{26}$. The treatment decision had to be made independently of data documentation and prior to the inclusion of the patients in this study.

We limited the analysis of the GO-NICE data to those with the diagnosis of established AS and who were biologic-naive, and we recorded the initial BASDAI values before the start of therapy with GOL $50 \mathrm{mg}$ subcutaneously once monthly. Patients were categorized into 3 groups: patients with BASDAI $\geq 4$ (Group 1); the third of patients with a BASDAI $<4$ was divided into 2 equal groups: BASDAI between 2.8 and $<4$ (Group 2), and BASDAI $<2.8$ (Group 3). Within each group, patients were split into those with elevated CRP value (above upper limit of normal, defined as $>5 \mathrm{mg} / \mathrm{l}$ ) versus non-elevated CRP. No radiographic data were collected in this observational study.

\section{RESULTS}

Patient disposition and flow is shown in Figure 1. Out of 543 patients with AS, 244 had not received any biologic medications for pretreatment and at least 1 documented followup visit after BL assessment and were thus eligible for analysis. Of these, 134 patients $(54.9 \%)$ completed the 24-month observational period (BL until visit at Month 24).

Male patients accounted for more than two-thirds in the sample (70.9\%). Mean time since diagnosis was $9.0 \pm 9.5$ years. Mean CRP values were significantly elevated (19.7 \pm $52.7 \mathrm{mg} / \mathrm{l})$, with substantial variety across patients.

At treatment initiation, the majority of patients $(70.5 \%)$ had BASDAI $\geq 4$ (Group 1), $14.3 \%$ had BASDAI of 2.8 to $<4$ (Group 2), and $15.2 \%$ had a BASDAI $<2.8$ (Group 3).

Patient demographics did not differ much between groups; the proportion of males was numerically lower in Group 1. Of note, the proportion of patients with an elevated CRP at BL was highest in Group 2 (Table 1).

Course of BASDAI over time. The mean BASDAI in Groups 1,2 , and 3 was initially $5.9 \pm 1.3,3.4 \pm 0.4$, and $2.0 \pm 0.8$, decreased to $2.2 \pm 2.0,1.9 \pm 1.2$, and $1.0 \pm 1.2$ within 3 months (all p $<0.0001 \mathrm{vs} \mathrm{BL}$ ), and decreased significantly to $2.2 \pm 1.7,1.9 \pm 1.7$, and $1.4 \pm 1.0$ at Month 24 (all $\mathrm{p}<0.005$ ), respectively (Figure 2).

In patients with a BASDAI $<2.8$ at BL (Group 3), the mean score was initially $2.0 \pm 0.8$ and further scores ranged from 0.7 to 1.9 , although some of the changes were not significant versus BL.

BASDAI 50\% improvement was noted in $68.8 \%, 44.8 \%$, and $45.2 \%$ of patients at Month 3 , and in $84.9 \%, 61.9 \%$, and $55.0 \%$ at Month 24, respectively.

Influence of CRP levels. CRP levels did not have an influence on BASDAI levels (Figures 3 and 4).

\section{DISCUSSION}

In this real-world study with unselected patients with AS who were biologic-naive and started TNFi GOL therapy, almost one-third of patients had BASDAI levels at BL that were below the recommended threshold of $\geq 4$. Thus, based on the current ASAS/EULAR recommendations, those patients would not have been eligible for such therapy. If correctly documented, this result suggests that rheumatologists recognize patients who, based on the level of inflammation present as evidenced by CRP levels or MRI findings, are in need of TNFi therapy but who judge themselves lower when ticking BASDAI boxes. This well-established questionnaire is an outcome variable that is solely based on subjective clinical symptoms. This is in contrast to the ASDAS, in which subjective variables are combined with CRP as an objective variable $^{12,13}$. However, patient's global assessment (PtGA) and ASDAS were not assessed in this study because it was

Personal non-commercial use only. The Journal of Rheumatology Copyright $\odot$ 2019. All rights reserved 


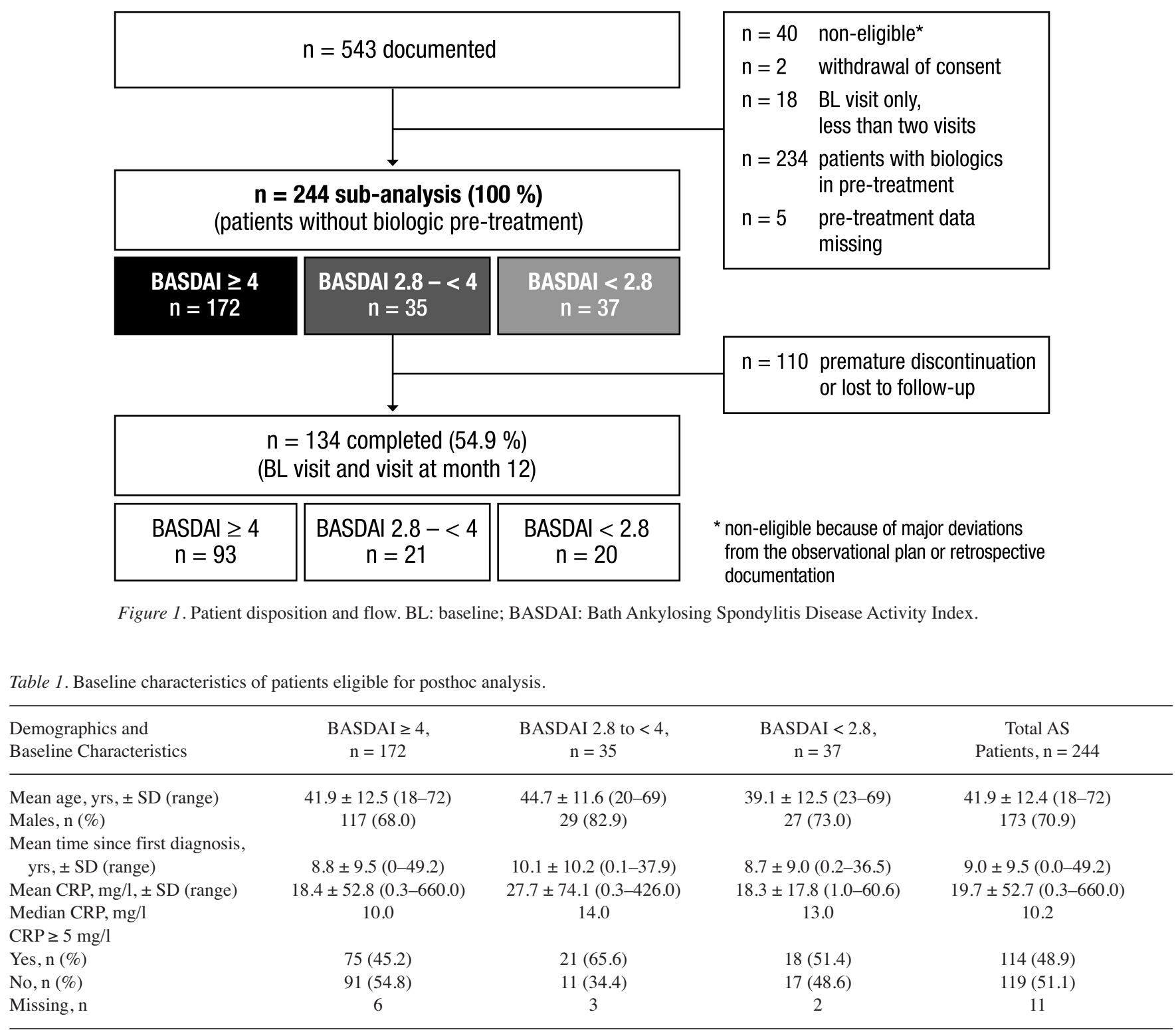

Table 1. Baseline characteristics of patients eligible for posthoc analysis.

BASDAI: Bath Ankylosing Spondylitis Disease Activity Index; AS: ankylosing spondylitis; CRP: C-reactive protein.

performed under clinical practice conditions, starting in 2010.

CRP levels in this study were higher in the groups with a low BASDAI (Groups 2 and 3). This suggests that rheumatologists sometimes weighted the presence of objective signs of inflammation higher than the subjective grading of clinical symptoms. This view is consistent with the treat-to-target concept $^{27,28}$ and also with the results of recent cohort studies. Thus, these data may lead to a critical reevaluation of the current BASDAI cutoff of $\geq 4$, because the burden of inflammation may, at least in some cases, be more important than the degree of clinical symptoms. This could be especially important for patients with high CRP and low BASDAI levels.

The other important observation of this study was that patients with relatively low BASDAI levels (between 2.8 and
4) still had a clear treatment response to TNFi. Absolute and relative treatment effects in patients with higher compared to lower initial BASDAI values were substantially stronger. This may be a real effect but could also represent an effect of regression to the mean ${ }^{29}$.

Because male sex ${ }^{30}$ and $\mathrm{CRP}^{16,17}$ may be associated with a better response to TNFi therapy, it seems possible that the high proportion of male patients and high CRP levels in the BASDAI 2.8-4 group has contributed to the significant treatment response in this group.

Our results are in line with a cross-sectional study performed between 2001 and 2003 in an experienced center in the UK. In that study, also about one-third of patients $(36 \%)$ did not meet the criteria for TNFi therapy according to recommendations at that time ${ }^{6}$. In a representative cohort 


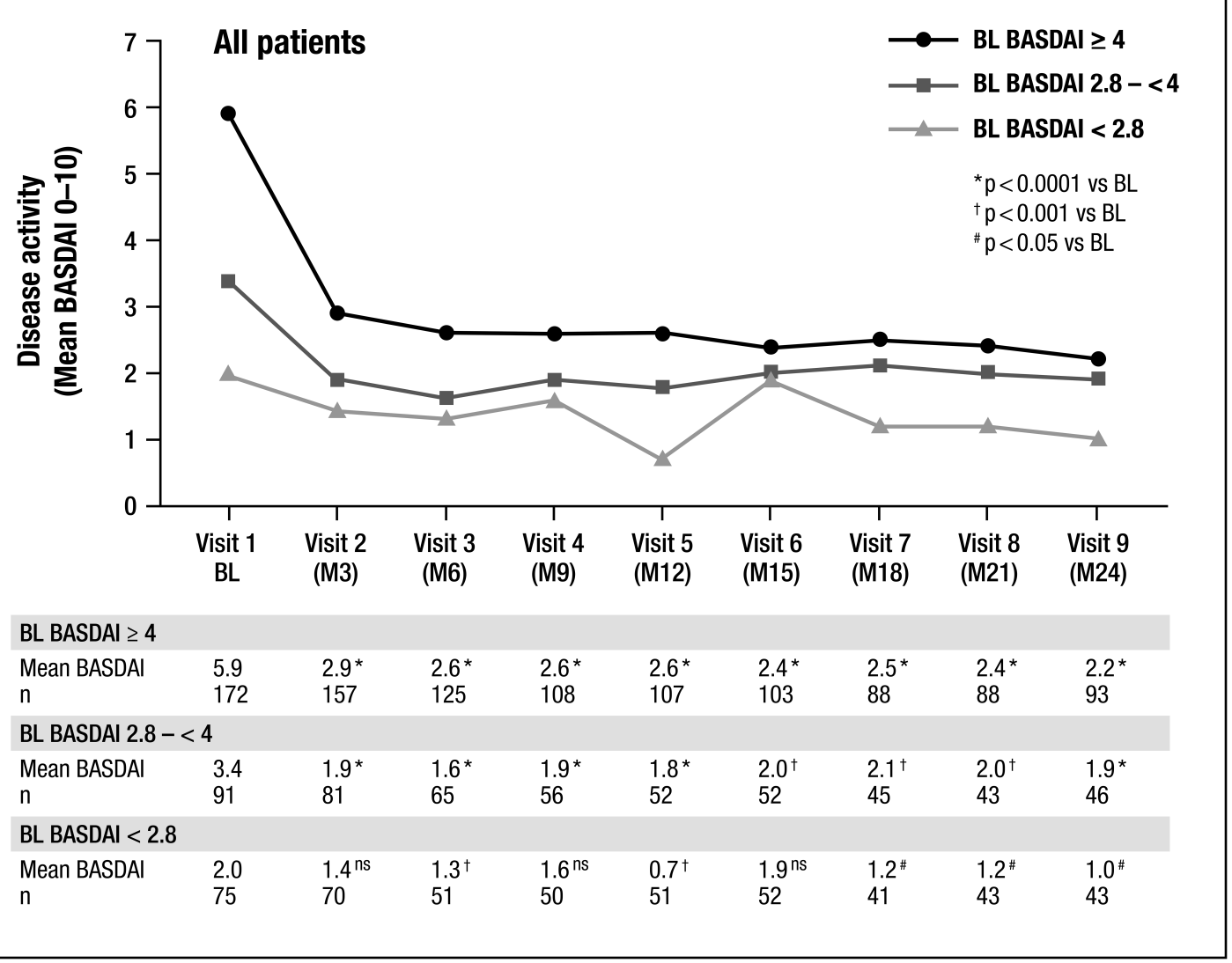

Figure 2. BASDAI course by subgroup. BASDAI: Bath Ankylosing Spondylitis Disease Activity Index; BL: baseline; M3: Month 3; ns: not significant.

of 1023 Belgian patients with AS evaluated by 89 rheumatologists in 2004/2005, about $60 \%$ did not commence TNFi therapy ${ }^{31}$. Although the recommendations for the treatment of patients with AS made an earlier start of TNFi treatment in the disease course possible, the BASDAI criterion $(\geq 4)$ for treatment has remained unchanged for almost 2 decades. The high proportion of patients with low disease activity receiving TNFi in this posthoc analysis of the GO-NICE study suggests that German rheumatologists are currently initiating biologic therapy differently.

Why rheumatologists decided to treat patients with lower BASDAI scores cannot be completely clarified. It seems possible that some patients who used to have higher scores in recent history had lower scores at BL assessment. Further, previous interventions prior to the BL assessment may have lowered BASDAI scores, for example, an intensive physiotherapy course ${ }^{32}$. Natural variation of symptoms and patient-reported outcome measures has been reported for patients with $\mathrm{AS}^{33}$.

Observed daily changes of BASDAI need to be interpreted with caution, however ${ }^{34}$. Patients with BASDAI $<2.8$ were not considered in detail in our analysis, because the BASDAI value shows considerable intrapatient week-to-week varia- bility; thus, repeat evaluations may be needed before starting or stopping $\mathrm{TNFi}^{35,36}$.

Our findings cannot be readily generalized, especially if a group has small patient numbers. That patients in this real-world study were treated with only $1 \mathrm{TNFi}$ does not exclude that they may have responded differently to other TNFi.

Differentiation within the BASDAI categories into normal versus high CRP did not change our overall findings. Patients with elevated versus not elevated CRP at BL in a cohort of 289 patients with AS had better responses to TNFi therapy according to all response measures, but patients without elevated CRP also responded ${ }^{37}$. This is consistent with the current approval situation for TNFi in patients with active AS.

Our study has some limitations, because it was noninterventional and thus was not randomized and had no control arm. The treating physicians may have selected patients to receive GOL as compared to other treatment options. This could lead to channeling bias and confounding by indication. The relatively high lost-to-followup rate, although well comparable with other studies, may also imply some statistical uncertainty. As described above, PtGA of the disease activity was not performed and thus ASDAS could not be calculated. 


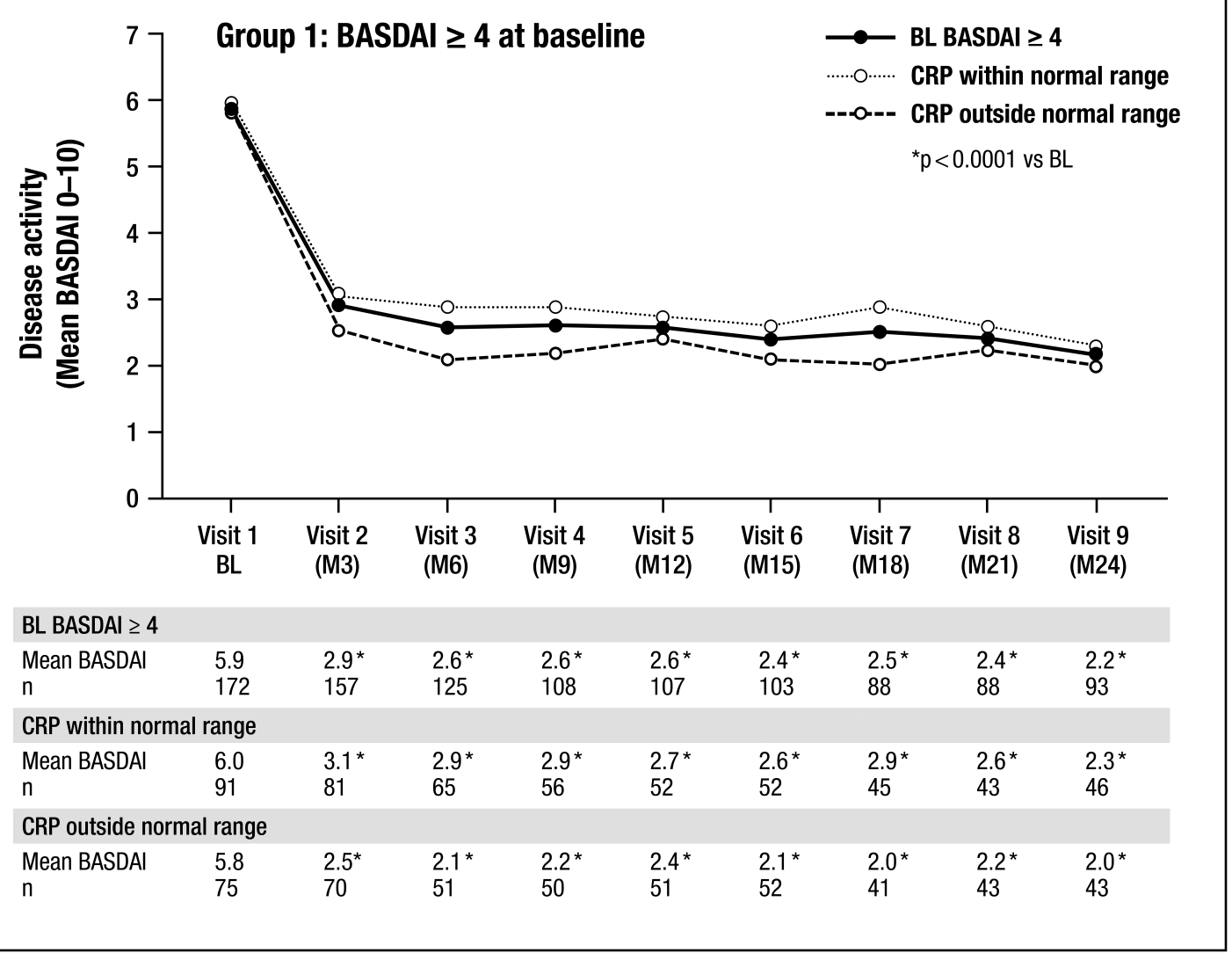

Figure 3. BASDAI course by Group 1 (subgroup BASDAI $\geq 4$ at BL) over time and C-reactive protein (CRP). BASDAI: Bath Ankylosing Spondylitis Disease Activity Index; BL: baseline; M3: Month 3.

The decision to start TNFi therapy always involves a combination of individualized risk, benefit, current signs and symptoms of the disease, patient characteristics, and costs. In our study, the primary reason to initiate therapy was not documented. Thus our data should be considered hypothesisgenerating, and different BASDAI cutoff values should be evaluated in prospective studies.

The most interesting observation of this posthoc analysis of a real-world study is that almost one-third of the patients included in this study were not documented as having reached the internationally recommended BASDAI cutoff of $\geq 4$. Further, the data show that the patients with a BASDAI 2.8 to $<4$ seem to have significant benefit of TNFi therapy, while this was not the case in patients with a BASDAI $<2.8$. This finding may lead to a reevaluation of the established BASDAI cutoff of $\geq 4$. Finally, CRP levels seem to have had no major influence on response rates.

\section{ACKNOWLEDGMENT}

We thank all the investigators and patients who participated in the GO-NICE study, and all members of the study team.

\section{REFERENCES}

1. Braun J, Sieper J. Ankylosing spondylitis. Lancet 2007;369:1379-90.
2. Wang R, Dasgupta A, Ward MM. Comparative efficacy of tumor necrosis factor-alpha inhibitors in ankylosing spondylitis: a systematic review and Bayesian network metaanalysis. J Rheumatol 2018;45:481-90.

3. Brandt J, Haibel H, Cornely D, Golder W, Gonzalez J, Reddig J, et al. Successful treatment of active ankylosing spondylitis with the anti-tumor necrosis factor alpha monoclonal antibody infliximab. Arthritis Rheum 2000;43:1346-52.

4. Garrett S, Jenkinson T, Kennedy LG, Whitelock H, Gaisford P, Calin A. A new approach to defining disease status in ankylosing spondylitis: the Bath Ankylosing Spondylitis Disease Activity Index. J Rheumatol 1994;21:2286-91.

5. Braun J, Brandt J, Listing J, Zink A, Alten R, Golder W, et al. Treatment of active ankylosing spondylitis with infliximab: a randomised controlled multicentre trial. Lancet 2002;359:1187-93.

6. Barkham N, Kong KO, Tennant A, Fraser A, Hensor E, Keenan AM, et al. The unmet need for anti-tumour necrosis factor (anti-TNF) therapy in ankylosing spondylitis. Rheumatology 2005;44:1277-81.

7. Cohen JD, Cunin P, Farrenq V, Oniankitan O, Carton L, Chevalier $\mathrm{X}$, et al. Estimation of the Bath Ankylosing Spondylitis Disease Activity Index cutoff for perceived symptom relief in patients with spondyloarthropathies. J Rheumatol 2006;33:79-81.

8. Pham T, Landewe R, van der Linden S, Dougados M, Sieper J, Braun $\mathrm{J}$, et al. An international study on starting tumour necrosis factor-blocking agents in ankylosing spondylitis. Ann Rheum Dis 2006;65:1620-5.

9. Braun J, Davis J, Dougados M, Sieper J, van der Linden S, van der Heijde D; ASAS Working Group. First update of the international

\section{Personal non-commercial use only. The Journal of Rheumatology Copyright @ 2019. All rights reserved.}




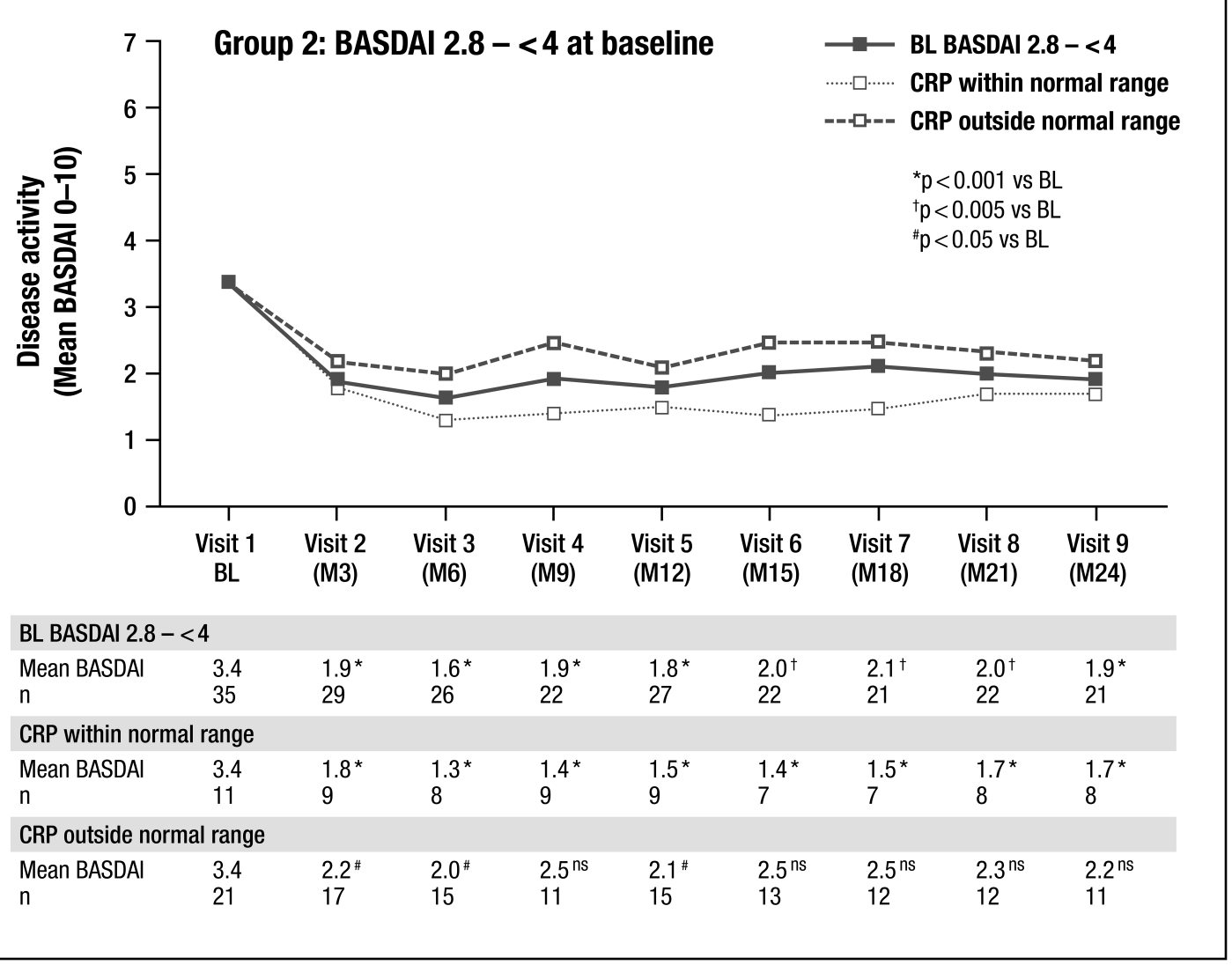

Figure 4. BASDAI course by Group 2 (subgroup BASDAI 2.8 to $<4$ at BL) over time and C-reactive protein (CRP). BASDAI: Bath Ankylosing Spondylitis Disease Activity Index; BL: baseline; M3: Month 3; ns: not significant.

ASAS consensus statement for the use of anti-TNF agents in patients with ankylosing spondylitis. Ann Rheum Dis 2006; 65:316-20.

10. Braun J, van den Berg R, Baraliakos X, Boehm H, Burgos-Vargas R, Collantes-Estevez E, et al. 2010 update of the ASAS/EULAR recommendations for the management of ankylosing spondylitis. Ann Rheum Dis 2011;70:896-904.

11. van der Heijde D, Ramiro S, Landewe R, Baraliakos X, Van den Bosch F, Sepriano A, et al. 2016 update of the ASAS-EULAR management recommendations for axial spondyloarthritis. Ann Rheum Dis 2017;76:978-91.

12. Lukas C, Landewe R, Sieper J, Dougados M, Davis J, Braun J, et al; Assessment of SpondyloArthritis international Society. Development of an ASAS-endorsed disease activity score (ASDAS) in patients with ankylosing spondylitis. Ann Rheum Dis 2009;68:18-24

13. van der Heijde D, Lie E, Kvien TK, Sieper J, Van den Bosch F, Listing J, et al; Assessment of SpondyloArthritis international Society (ASAS). ASDAS, a highly discriminatory ASAS-endorsed disease activity score in patients with ankylosing spondylitis. Ann Rheum Dis 2009;68:1811-8.

14. Kiltz U, Baraliakos X, Karakostas P, Igelmann M, Kalthoff L, Klink $\mathrm{C}$, et al. The degree of spinal inflammation is similar in patients with axial spondyloarthritis who report high or low levels of disease activity: a cohort study. Ann Rheum Dis 2012;71:1207-11.

15. Poddubnyy DA, Rudwaleit M, Listing J, Braun J, Sieper J. Comparison of a high sensitivity and standard $\mathrm{C}$ reactive protein measurement in patients with ankylosing spondylitis and non-radiographic axial spondyloarthritis. Ann Rheum Dis 2010;69:1338-41.

16. Rudwaleit M, Listing J, Brandt J, Braun J, Sieper J. Prediction of a major clinical response (BASDAI 50) to tumour necrosis factor alpha blockers in ankylosing spondylitis. Ann Rheum Dis 2004;63:665-70.

17. de Vries MK, van Eijk IC, van der Horst-Bruinsma IE, Peters MJ, Nurmohamed MT, Dijkmans BA, et al. Erythrocyte sedimentation rate, $\mathrm{C}$-reactive protein level, and serum amyloid a protein for patient selection and monitoring of anti-tumor necrosis factor treatment in ankylosing spondylitis. Arthritis Rheum 2009; 61:1484-90.

18. Poddubnyy D, Protopopov M, Haibel H, Braun J, Rudwaleit M, Sieper J. High disease activity according to the Ankylosing Spondylitis Disease Activity Score is associated with accelerated radiographic spinal progression in patients with early axial spondyloarthritis: results from the GErman SPondyloarthritis Inception Cohort. Ann Rheum Dis 2016;75:2114-8.

19. Ware JE Jr, Sherbourne CD. The MOS 36-item short-form health survey (SF-36). I. Conceptual framework and item selection. Med Care 1992;30:473-83.

20. Inman RD, Davis JC Jr, Heijde D, Diekman L, Sieper J, Kim SI, et al. Efficacy and safety of golimumab in patients with ankylosing spondylitis: results of a randomized, double-blind, placebo-controlled, phase III trial. Arthritis Rheum 2008; 58:3402-12. 
21. van der Heijde D, Deodhar A, Braun J, Mack M, Hsu B, Gathany TA, et al; GO-RAISE investigators. The effect of golimumab therapy on disease activity and health-related quality of life in patients with ankylosing spondylitis: 2-year results of the GO-RAISE trial. J Rheumatol 2014;41:1095-103.

22. Braun J, Baraliakos X, Hermann KG, Xu S, Hsu B. Serum C-reactive protein levels demonstrate predictive value for radiographic and magnetic resonance imaging outcomes in patients with active ankylosing spondylitis treated with golimumab. J Rheumatol 2016;43:1704-12.

23. Krüger K, Burmester G, Wassenberg S, Bohl-Bühler M, Thomas M. Effectiveness and safety of golimumab in patients with rheumatoid arthritis, psoriatic arthritis and ankylosing spondylitis under real-life clinical conditions: non-interventional GO-NICE study in Germany. BMJ Open 2018;8:e021082.

24. Krüger K, Burmester GR, Wassenberg S, Bohl-Buhler M, Thomas $\mathrm{MH}$. Patient-reported outcomes with golimumab in patients with rheumatoid arthritis, psoriatic arthritis, and ankylosing spondylitis:non-interventional study GO-NICE in Germany. Rheumatol Int 2019;39:131-40.

25. Brandt J, Westhoff G, Rudwaleit M, Listing J, Zink A, Braun J, et al. [Adaption and validation of the Bath Ankylosing Spondylitis Disease Activity Index (BASDAI) for use in Germany]. [Article in German] Z Rheumatol 2003;62:264-73.

26. European Medicines Agency. Simponi. [Internet. Accessed May 2, 2019.] Available from: www.ema.europa.eu/en/medicines/human/EPAR/simponi

27. Smolen JS, Braun J, Dougados M, Emery P, Fitzgerald O, Helliwell $\mathrm{P}$, et al. Treating spondyloarthritis, including ankylosing spondylitis and psoriatic arthritis, to target: recommendations of an international task force. Ann Rheum Dis 2014;73:6-16.

28. Smolen JS, Schols M, Braun J, Dougados M, FitzGerald O, Gladman DD, et al. Treating axial spondyloarthritis and peripheral spondyloarthritis, especially psoriatic arthritis, to target: 2017 update of recommendations by an international task force. Ann Rheum Dis 2018;77:3-17.
29. Morton V, Torgerson DJ. Effect of regression to the mean on decision making in health care. BMJ 2003;326:1083-4.

30. Rusman T, van Vollenhoven RF, van der Horst-Bruinsma IE. Gender differences in axial spondyloarthritis: women are not so lucky. Curr Rheumatol Rep 2018;20:35.

31. Vander Cruyssen B, Ribbens C, Boonen A, Mielants H, de Vlam K, Lenaerts $\mathrm{J}$, et al. The epidemiology of ankylosing spondylitis and the commencement of anti-TNF therapy in daily rheumatology practice. Ann Rheum Dis 2007;66:1072-7.

32. van Tubergen A, Landewe R, van der Heijde D, Hidding A, Wolter $\mathrm{N}$, Asscher M, et al. Combined spa-exercise therapy is effective in patients with ankylosing spondylitis: a randomized controlled trial. Arthritis Rheum 2001;45:430-8.

33. Stone MA, Pomeroy E, Keat A, Sengupta R, Hickey S, Dieppe P, et al. Assessment of the impact of flares in ankylosing spondylitis disease activity using the Flare Illustration. Rheumatology 2008;47:1213-8.

34. Madsen OR. Stability of fatigue, pain, patient global assessment and the Bath Ankylosing Spondylitis Functional Index (BASFI) in spondyloarthropathy patients with stable disease according to the Bath Ankylosing Spondylitis Disease Activity Index (BASDAI). Rheumatol Int 2018;38:425-32.

35. Berthelot JM, Tortellier L, Lavy-Bregeon D, Le Goff B, Maugars Y. High intraindividual week-to-week variability in BASDAI and BASFI values: are several evaluations needed before starting or stopping TNFalpha antagonist therapy for spondyloarthropathies? Joint Bone Spine 2008;75:167-71.

36. Essers I, Boonen A, Busch M, van der Heijde D, Keszei AP, Landewe R, et al. Fluctuations in patient reported disease activity, pain and global being in patients with ankylosing spondylitis Rheumatology 2016;55:2014-22.

37. Fagerli KM, Lie E, van der Heijde D, Heiberg MS, Kaufmann C, Rodevand E, et al. Selecting patients with ankylosing spondylitis for TNF inhibitor therapy: comparison of ASDAS and BASDAI eligibility criteria. Rheumatology 2012;51:1479-83. 